\title{
LUTA, NEGOCIAÇÃO E RESISTÊNCIA DA COMUNIDADE TUXÁ NO PROCESSO DE REASSENTAMENTO, ENTRE 1980-1990
}

\author{
Erêndira Santos da Silva ${ }^{1}$; Eurelino Teixeira Coelho Neto ${ }^{2}$ \\ 1. Bolsista PIBIC/CNPq, Graduanda em História, Universidade Estadual de Feira de Santana, e-mail: \\ erendirasilva20@gmail.com \\ 2. Orientador, Departamento de Ciências Humanas e Filosofia, Universidade Estadual de Feira de Santana, e-mail: \\ eurecoelho@uefs.br
}

PALAVRAS-CHAVE: território; territorialização; desterritorialização.

\section{INTRODUÇÃO}

Esta pesquisa tem por objetivo geral analisar o processo de desterritorialização da comunidade Tuxá, nação Proká Pragaga do Arco e Flecha e Maracá Malacutinga Tuá Deus do $A r$. ocasionada pela instalação da Usina Hidrelétrica Luiz Gonzaga. A aldeia Tuxá localizada em terra firme no município de Rodelas e a ilha de viúva na calha do rio são Francisco, espaços que desenvolviam sua base produtiva e as praticas ritualísticas foram completamente inundados.

Os Tuxá são remanescentes de povos aldeados da Missão de São João Batista de Rodelas, uma das últimas a serem extintas no século XIX, e que habitavam em média 25 ilhas localizadas nas imediações entre Chorochó e o Rio Pajeú. É na tradição e na sacralidade desenvolvida em relação simbiótica com o território, que se encontra o cerne da organização dessa comunidade. Atualmente, a comunidade é constituída de 214 famílias, cerca de 995 indivíduos, espacialmente estão distribuídos em Nova Rodelas e em fazendas próximas à cidade de Ibotirama e Inajá.

A usina hidrelétrica Luiz Gonzaga (antiga Itaparica) construída em 1979, foi dirigida e executada pela Companhia Hidrelétrica do São Francisco- CHESF, com a justificativa de atender a demanda por energia dos polos industriais de Recife, Salvador e regiões circunvizinhas. A construção do reservatório em 1988 inundou cerca de 834,0 Km, ${ }^{2}$ deslocando compulsoriamente mais de 40.000 pessoas, dentre eles 1.200 indígenas Tuxá, e segundo Salomão (2006), atingiu vários municípios, como Rodelas, Glória e Petrolândia-Pe, que foram inteiramente alagados.

A alteração espacial desse território gerou também mudanças sociais, atingindo de diferentes maneiras vários grupos humanos, englobando os Tuxá, o projeto gerou sérias implicações, como o processo de desterritorialização, sobreposição de duas reservas indígenas e o desmembramento do sistema de produção e organização que se reverbera até os dias atuais. Analisar como se configurou o processo de desterritorialização em que os Tuxá foram submetidos, incide em saber a quem realmente interessava esse desenvolvimento nacional e que tipo de politica territorial estava em jogo. Além disso, poucos são as pesquisas em relação ao modo como esses indígenas foram atingidos e como reagiram às intervenções e ao plano de desocupação, que é no cerne desse problema que situamos nesse estudo.

\section{MATERIAL E MÉTODOS}

As fontes utilizadas na elaboração da pesquisa foram: lei $\mathrm{n}^{\circ} 6.001$, de 19 de dezembro de 1973 e a lei $n^{\circ}$ 601, de 18 de setembro de 1850, que dispõem respectivamente sobre o Estatuto do Índio e as terras devolutas do Império. Os periódicos foram o caderno de Estudos Sociais, o Diário de Pernambuco e decretos do conselho ultramarino. Para análise do objeto de estudo, dialogamos com os campos semânticos da etnologia e da geografia. Partimos do conceito de território como "o fundamento do trabalho, o lugar da residência, das trocas materiais e espirituais e do exercício da vida" (Santos, 2002), ou seja, um reflexo da 
identidade coletiva de determinado grupo, e que se constitui a partir das relações sociais estabelecidas e das intervenções que fazem no território.

Para compreender como o território assumiu dimensões e sentidos diferentes por grupos que estavam situados em universos simbólicos diferentes, empregamos o conceito de territorialização, a partir de Oliveira (1999), que estabelece que o processo de constituição da territorialização perpassa uma reorganização social, no qual os sujeitos irão reelaborar sua identidade a partir de outras identidades diferenciadoras e de novos elementos socioculturais. Consideramos como desterritorialização, as ações exógenas sobre um território, gerando o desmembramento do sistema organizacional e expropriando os sujeitos ali existentes. Empregamos o conceito 'espaço produzido' estabelecido por Andrada (1982) para analisar as alterações do espaço rural e urbano na dinâmica do desenvolvimento industrial no Nordeste.

\section{RESULTADOS E/OU DISCUSSÃO}

A construção da usina hidrelétrica Luiz Gonzaga foi parte das inúmeras intervenções realizadas nas calhas do rio São Francisco, que tinha como política territorial a reorganização dos espaços, para ampliação e centralização da produção elétrica, com o objetivo de integrar os projetos regionais à economia nacional. Com a formação do reservatório da UHE em 1988, as ilhas fluviais localizadas entre Chorochó e o rio Pajéu, território originário dos Tuxá, foram inteiramente alagados. Especialmente a ilha de viúva que nesse período servia como espaço de manutenção do seu sistema produtivo e de suas práticas ritualísticas. Devido a isso, os Tuxá tiveram que ser transferidos forçadamente para outros locais, e transferência foi realizada ainda durante os processos de negociação.

Os primeiros acordos foram realizados em 1986 e 1987, e definia as primeiras diretrizes do reassentamento. A negociação foi realizada apenas entre a CHESF e a FUNAI, possivelmente os Tuxá não participaram, pois a política tutelar e protecionista do período considerava os indígenas inabilitados, por estarem em processo de assimilação e integração à sociedade civil. É o que podemos ver no Estatuto do Índio, outorgado pela lei no 6.001 , de 19 de dezembro de 1973:

Art. $2^{\circ}$ Cumpre à União, aos Estados e aos Municípios, bem como aos órgãos das respectivas administrações indiretas, nos limites de sua competência, para a proteção das comunidades indígenas e a preservação dos seus direitos: II - prestar assistência aos índios e às comunidades indígenas ainda não integrados à comunhão nacional; (Brasil, 1973)

Autores como Cruz (2017: 101), reiteram que a inundação da reserva indígena dos Tuxá encontrava respaldo neste mesmo Estatuto, que em seu $\operatorname{art}^{\circ} 20$ abria prerrogativas para construção de grandes obras públicas de interesse nacional:

Art. 20. Em caráter excepcional e por qualquer dos motivos adiante enumerados, poderá a União intervir, se não houver solução alternativa, em área indígena, determinada a providência por decreto do Presidente da República. $1^{\circ}$ A intervenção poderá ser decretada: d) para a realização de obras públicas que interessem ao desenvolvimento nacional. (Brasil, 1973)

Os impactos gerados pela barragem da UHE de Itaparica não tiveram a mesma ressonância sobre os diversos grupos sociais atingidos, pois as ações sobre o território e as relações de territorialidade se realizavam de maneiras distintas. Mesmo no interior da própria 
comunidade Tuxá, os impactos da desterritorialização foram sentidos e reagidos de maneiras distintas pelos grupos familiares, o que levou ao conflito e a fragmentação do grupo. Os Tuxá foram divididos em três grupos, o que resultou em projetos de reassentamentos diferentes, o primeiro grupo foi reassentado nas fazendas de Morrinhos e Oiteiros, em Ibotirama; o segundo foi reassentado na cidade de Inajá; e o terceiro, que foi transferido para Novas Rodela (atualmente, intitulada aldeia Tuxá mãe Rodelas) com a promessa de permanecer apenas seis meses no acampamento da CHESF, até a compra e demarcação da reserva indígena foi relegado e a luta se mantém até os dias atuais.

Após quase 27 anos de desterritorialização, os indígenas de Rodelas estão em condições socioeconômicas inferiores, quando comparadas ao período anterior à construção da UHE de Itaparica, dependendo quase que exclusivamente da V.M.T. - Verba de Manutenção Temporária - que recebem da CHESF.

\section{CONSIDERAÇÕES FINAIS}

Embora a pesquisa não tenha alcançado os efeitos desejados por não termos conseguido acessar os documentos que estão localizados no acervo da CHESF, e produzir todas as fontes orais necessárias para os objetivos elencados. Acreditamos que a ampla revisão bibliográfica realizada apontou indicadores fundamentais no andamento da investigação. Inferimos que a ocupação do território Tuxá pela CHESF foi assegurado juridicamente devido às prerrogativas da lei $\mathrm{n}^{\circ}$ 6.001, de 19 de dezembro de 1973, que permitia em nome do desenvolvimento nacional a intervenções na área. $O$ plano de desocupação dos Tuxá, devido à fragmentação do grupo, gerou três reassentamentos em locais e períodos diferentes, sendo as lutas empreendidas de formas separadas, e por último, que a espoliação da terra pela barragem de Itaparica foi apenas mais um fenômeno de desterritorialização que acompanhou a trajetória desses sujeitos.

\section{REFERÊNCIAS}

Tradição e Mudança. A organização do espaço rural e urbano na área de irrigação do submédio São Francisco. Rio de Janeiro, Zahar, 1982, p114.

ALMEIDA, Dorival V. Sociedades indígenas na rota do desenvolvimento: Os índios Tuxá de Rodelas e a formação do lago de Itaparica em 1988. Feira de Santana: UEFS, 2011, p. 63.

ANDRADE, Manuel Correia de. Estado, capital e industrialização do Nordeste. Rio de Janeiro: Zahar Editores, 1981

CRUZ, F. S. M. Quando a terra sair' Os Índios Tuxá de Rodelas e a barragem de Itaparica: Memórias do desterro, memórias da resistência. Dissertação (Mestrado em Antropologia)Instituto de Ciências Sociais, Universidade de Brasília, Brasília, 2017, p. 143

MALDI, Denise. A questão da territorialidade na etnologia brasileira. Sociedade e Cultura, 1 (1):1-17, jan/jun, 1998.

OLIVEIRA, João Pacheco. A problemática dos "índios misturados" e os limites dos estudos americanistas: um encontro entre antropologia e história. In: Ensaios de Antropologia Histórica. Rio de Janeiro: Editora UFRJ, 1999.

SALOMÃO, Ricardo D. B. Etnicidade, territorialidade e ritual entre os Tuxá de Rodelas. Dissertação (Mestrado) em Antropologia Social pela Universidade Federal Fluminense. Niterói, 2006 , p. 188.

SANTOS, Milton. O território e o dinheiro. In: Território, Territórios. Niterói: PPGEO / AGB, 2002.

SCOTT, R. P. Negociações e Resistência Persistentes: agricultores e a barragem de Itaparica num contexto de descaso planejado. 1. ed. Recife: Editora Universitária da UFPE, 2009. v. 1. $290 \mathrm{p}$ 
VIEIRA, É. F. S.; SANTOS, Rosângela Leal. Alterações no Território e Repercussões na Territorialidade: A Relocação do Povo Tuxá - Bahia. In: Anais XVII Simpósio Brasileiro de Sensoriamento Remoto - SBSR, João Pessoa-PB, Brasil, 25 a 29 de abril de 2015, INPE, p.7133-7140. 